\title{
UNA PERSONIFICACIÓN DEL IDEAL CABALLERESCO EN EL MEDIEVO TARDÍO: DON ALONSO DE ARAGÓN
}

\author{
SOPHIA MENACHE
}

Universidad de Haifa

La Reconquista Española enriqueció el ideal caballeresco medieval, cuando la epopeya del Mío Cid consolidó la aureola mítica de Rolando, creando los componentes básicos del estereotipo del caballero medieval. La lucha contra los infieles, raison d'être de ambos, llegó a su cúspide con el movimiento cruzado. La llamada de Urbano II desde el concilio de Clermont, aparejada con la añoranza ancestral hacia la Tierra Santa, crearon un desafío y una meta para los caballeros medievales, quienes durante dos centurias se vieron involucrados en los altibajos de los Reinos Cruzados del Levante (1). La dedicación a la Guerra Santa fue sólo una faceta del ideal caballeresco medieval, si bien la más fomentada por el estamento eclesiástico. La cultura popular, profundamente enraizada en la tradición germánica, continuó manteniendo vivos los ideales de intrepidez en el campo de batalla, a pesar de las continuas sanciones eclesiásticas (2), el culto del bello sexo y por sobre todo, la fidelidad indestructible y absoluta del caballero hacia su señor feudal.

La esencia normativa de la sociedad medieval mantuvo indemne el ideal caballeresco en el plano teórico (3). No así en el plano práctico, donde los caballeros se vieron afectados por la evolución política y social del medievo tardío, que relegó a la Guerra Santa a una posición marginal. Dicha evolución, general a la sociedad europea, tuvo amplias consecuencias en el ámbito peninsular. El caballero español del siglo XV se vio paulatinamente liberado de la lucha contra los Infieles y sus servicios fueron en más requeridos por corrientes políticas divergentes, entre las cuales la lucha continua entre Castilla y Aragón y el conflicto agudo entre parcialidades políticas, ocuparon 
un lugar de preferencia (4). Éstas fueron las circunstancias históricas en las cuales actuó nuestro biografiado, Don Alonso de Aragón (1421?-1485). Hijo natural del Infante Don Juan, futuro rey de Navarra y de Aragón, sobrino del rey Juan II de Castilla, de Alfonso V de Aragón y Duarte de Portugal, hermanastro de Fernando el Católico, Don Alonso fue llevado por su alta cuna al epicentro de la efervescencia política y militar de la península. No obstante, la historia de Don Alonso se ha mantenido hasta el presente en una nebulosa historiográfica. La investigación moderna, amén del estudio pionero de José Navarro Latorre (5), no ha hecho suficiente uso de los datos inconexos que nos presentan las crónicas medievales.

El objetivo del presente estudio es articular la biografía de don Alonso de Aragón desde el prisma analítico del ideal caballeresco medieval (6). Las fuentes contemporáneas justifican ampliamente dicha premisa. El Memorial de Diversas Hazañas, por ejemplo, describe a Don Alonso como «muy valiente y esforçado cavallero" y destaca sus continuos servicios para con su padre, Juan de Navarra. Dicho juicio fue aceptado por Andrés Bernáldez, quien añadió a su vez: «e de muy gran consejo para la guerra», mientras $A$. de Palencia lo describe como «bravo guerrero, muy digno de tal padre» (7). En este punto es menester avanzar una aclaración metodológica. El relativamente largo período de tiempo cubierto por la biografía de Don Alonso de Aragón así como la efervescencia política y militar de su época, justifican una visión selectiva del proceso histórico. De alli que hemos tratado de mantener el foco de nuestra investigación en nuestro biografiado, dirigiendo al lector interesado a la amplia investigación histórica del período.

Don Alonso de Aragón fue fruto de los amores entre el Infante Don Juan, a la sazón Duque de Peñafiel, y Doña Leonor de Escobar, hija de noble familia del cortejo de la reina madre, quien se recogió posteriormente en el Monasterio de Santa Maria de Dueñas de Medina del Campo (8). La fecha del nacimiento de Don Alonso es incierta. Su biógrafo le adjudica la edad de 22 años en 1443, cuando fue electo Maestre de Calatrava (9). Por otra parte, la dispensación papal otorgada en dicha ocasión por Eugenio IV, no hace mención de su edad (10). En un documento posterior (1455) el papa Calixto III le adjuđicó a Don Alonso la edad de 14 años cuando tomó posesión del Maestrazgo de Calatrava (11). De allí que el nacimiento de Don Alonso se sitúa entre los años 1421 y 1429 . Bajo la tutela de su tío, Juan II de Castilla, fue enviado a temprana edad a la corte del rey Duarte de Portugal, donde recibió los primeros cimientos de su educación de caballero. Llamado de regreso a la corte castellana, fue ordenado caballero por el rey, de quien recibió su escudo de armas «partido en tres cuarteles; en los dos de la mano derecha un 
castillo de oro en campo colorado y en la otra parte más abaxo un león coronado medio morado y medio roxo en campo blanco y en el otro medio escudo las armas reales de Aragón con sus colores naturales que son las cinco barras doradas en campo colorado. Después desto añadió al escudo por encima de las armas una cruz larga entre el escudo y corona quando fue electo Maestre de Calatrava» (12).

La vida de Don Alonso en estos años se pierde en el torbellino político que afectaba a Castilla. Su biografía nos lo describe peleando «como un león» en las distintas escaramuzas que se presentaron al lado de los Infantes de Aragón, «siendo tan contínuos los encuentros con cuyo exercicio salió consumado soldado y el más experimentado capitán y de mayores azañas que igualó con ellas a sus pasados y les excedió, como el Rey su padre y todos los españoles y franceses de común consentimiento solían decir. A esto se acompañó las partes personales que le hicieron lucir mucho porque fue de muy buen rostro y lindos ojos, pelo castaño, de gentil estatura. Más grande que pequeño, robusto, gran brazero, buen hombre de acaballo de entrambas sillas y gran hombre de armas, siendo temido por el encuentro de su lanza. Con todo esto mereció los grandes favores que el Rey su tío le hiço y el los alcanzó por sus servicios particulares» (13).

Los favores reales aludidos en la cita precedente se refieren, primordialmente, a la intervención de Juan II para asegurar el Maestrazgo de Calatrava en la persona de su sobrino, a pesar de la oposición de los dignatarios de la orden. Superados los impedimentos de edad, nacimiento y profesión (14), las gestiones del rey de Castilla sumadas a la presión militar de los Infantes de Aragón, dieron fruto el 18 de agosto de 1443, cuando Don Alonso fue electo oficialmente en maestre de la importante orden militar castellana (15). La elección de Don Alonso de Aragón en Maestre de Calatrava, refleja nítidamente la constelación política imperante. La derrota del rey castellano Juan II y su favorito, el condestable Álvaro de Luna en Medina del Campo (28 de junio de 1441) había llevado a los líderes de la Liga Castellana, los Infantes de Aragón, al epicentro del poder en Castilla, desde donde contaban con la cooperación incondicional de su real primo. Más aún, el levantamiento de Rámaga que había llevado al virtual emprisionamiento del rey de Castilla (19 de julio de 1443), había convertido a los Infantes de Aragón en los gobernantes efectivos del reino (16).

No obstante, el maestrazgo de Don Alonso, condicionado desde sus comienzos al provisorio poderio de sus allegados, resultó una etapa pasajera en las lides políticas de Castilla. Ya en 1444, la alianza entre el condestable Álvaro de Luna y el heredero al trono, Enrique Príncipe de Asturias, despertó 
los primeros cargos en contra de la validez de la nominación. Los dignatarios de Calatrava elevaron sus quejas frente a Don Gutierre, Arzobispo de Toledo. Dichos cargos fueron formalmente confirmados por Juan II, quien, una vez recuperada su libertad personal y vencedor en la batalla de Olmedo (19 de mayo de 1445), incentivó la formal destitución de Don Alonso por el capítulo de la orden. Paralelamente, el rey castellano patrocinó la elección de $\mathrm{Pe}$ dro Girón, quien fue electo maestre el 19 de septiembre de 1445 (17). A pesar que Don Alonso de Aragón gozó menos de un año de la posesión efectiva del Maestrazo de Calatrava, el oficio pasajero dejó huellas profundas en su vida. Formalmente continuó usando el título de maestre durante los próximos treinta años, cuando a la vez que era agraciado con el título ducal de Villahermosa (1475), contrajo enlace matrimonial, que lo descartó por completo de la alta dignidad eclesiástica (18). Más aún, la experiencia del maestrazgo no sólo fructificó las aptitudes militares de Don Alonso sino que también le brindó una nueva conciencia del poder, a través de su liderazgo de la poderosa orden castellana (19).

Al respecto de su destitución del maestrazgo de Calatrava, cabe citar la interpretación que nos brinda la biografía de Don Alonso de Aragón: «...pero habiéndole menester el Rey Don Juan su padre para la guerra que contra el Príncipe Don Carlos su hijo y hermano del maestre tenía, no obstante que el Rey Don Juan de Castilla faborecía al Príncipe Don Carlos, a quien él como Maestre debía asistir por los beneficios recividos y tenerle prestado juramento al Rey de obediencia por Maestre de Calatrava, reconociendo también los intentos de Don Pedro Téllez Jirón salido del Rey en la pretensión del Maestrazgo y que lo abenturaba si acudía al llamamiento de su padre, antepusso a todas estas razones la obediencia que le debia, conociendo muy bien que no podía hallar recompensa del Maestrazgo. Y parece que en aquel tiempo no estaba tan válida la razón de Estado como oy se ve pues pudiera haberse conservado el Maestre con su padre y su tío guardando neutralidad, pues los beneficios que tenía recividos del Rey Don Juan de Castilla su tío pudieran ser suficiente razón para suspender el yr al llamamiento de su padre, sabiendo era forçoso el pelear contra las armas de Castilla y incurrir en desobediencia de aquel Rey a quien tanto debía, perdiendo por esto el gozo del Maestrazgo como sucediós (20).

Si bien la biografía antepone el conflicto con el príncipe de Viana en seis años, esclarece fielmente el conflicto de intereses que llevó a la destitución de Don Alonso de Aragón. La abierta identificación del maestre con el partido representado por los Infantes de Aragón crearon una incompatibilidad política con su señor y rey, Juan II de Castilla. El apologético tono que acompa- 
ña el tenor de la biografía respecto a la actuación de Don Alonso, parecería destinado a justificar la incuria de nuestro héroe hacia su soberano, el rey castellano, al cual había prestado juramento y homenaje. Desde la perspectiva de nuestro anónimo autor, la apatía de Don Alonso a sus propios intereses aparejada por su abnegada dedicación filial a Juan de Navarra, aparecen como fuerzas de peso que balancean la traición incurrida al código caballeresco ancestral: fidelidad al señor feudal.

Por otra parte, la destitución del maestrazgo puede ser considerada como vaticinio del futuro político de Don Alonso de Aragón. Si bien Juan de Navarra aseguró en la práctica el gobierno de su hijo natural en las encomiendas de Alcañiz (19), a partir de 1445 hasta su muerte acaecida en 1485, Don Alonso se brindó incondicionalmente a las lides de su familia, de su progenitor y señor, Don Juan de Navarra y posteriormente de su hermanastro, Fernando el Católico. De allí que la renunciación forzada al Maestrazgo de Calatrava no involucró un revés en la carrera militar de Don Alonso; éste siguió contando con el apoyo de los caballeros aragoneses, amén del sostén de su beligerante padre. Más aún, las dotes militares de Don Alonso y su fidelidad hacia la causa aragonesa fueron prontamente reconocidas por Alfonso $\mathrm{V}$, quien desde sus lejanos reinos italianos aconsejaba al irascible Juan de Navarra que encomendase a Don Alonso toda empresa militar futura en el reino de Castilla (21). Los consejos del rey aragonés fueron llevados a la práctica a comienzos de 1449, cuando se brindó a Don Alonso la dirección de la ofensiva Juanista contra Cuenca, destinada a preparar el ataque contra Murcia. El ejército que se encomendó a Don Alonso contaba con 6.000 gente de armas, jinetes, ballesteros y lanceros. Al lado de Don Alonso participaron veteranos capitanes aragoneses y castellanos como Juan de Hijar, Pedro de Urrea, Juan de Lanuza, Ferrer de Bardaxi, Martín de Ansa, Juan Fernández de Heredia, Gómez Manrique, Rodrigo Rebolledo, Hernando de Rojas y Diego Gómez de Sandoval (22). No obstante, el bajo nivel combativo de los reclutados, en su mayor parte labradores valencianos y mudéjares, llevó al primer revés militar en la brillante carrera de Don Alonso (23).

El revés de las huestes Juanistas frente a la valerosa defensa de Lope de Barrientos y la población conquense, frustró los planes de un inmediato golpe de Estado en Castilla. Dicha situación indujo a Don Juan a fortalecer su posición en Navarra como posible plataforma ofensiva en el futuro. Mas, el regreso de Juan de Navarra a su reino a comienzos de 1450, sumado a las intrigas del condestable castellano Álvaro de Luna, dificultaron las ya tensas relaciones entre el rey y su primogénito, Carlos Príncipe de Viana, quien habia gozado del virtual gobierno de Navarra desde la muerte de su madre, 
doña Blanca, acaecida en 1441 (24). Más aún, la supuesta entente castellanonavarrense (Estella, septiembre de 1451) fue interpretada por Juan de Navarra como casus belli. Convencido de la traición del príncipe de Viana y sus manejos con Castilla, Juan de Navarra promovió la alternativa bélica, que daría lugar a la batalla de Aybar (23 de octubre de 1451).

La superioridad numérica del ejército Vianista en Aybar era evidente. A los contingentes beamonteses y lusitanos, se les sumaron cuatrocientos hombres de armas y seiscientos jinetes castellanos enviados por Juan II y el Príncipe de Asturias. No obstante, el valor de los capitanes del ejército Juanista, Rodrigo de Rebolledo y Don Alonso de Aragón, permitió conseguir la importante victoria, que se vería coronada con el emprisionamiento del príncipe de Viana (25). En su reseña histórica de la lucha fratricida, Zurita trae dos versiones respecto a la actuación de Don Alonso de Aragón y su participación en el emprisionamiento del príncipe de Viana. Si bien en ambas versiones Don Alonso aparece como héroe indiscutido en el campo de batalla, se vislumbran pequeñas diferencias respecto a la actitud de Don Carlos hacia su hermanastro. La primera versión refiere la valentía y arrojo de Don Alonso, quien logró cambiar el curso de la batalla con sólo treinta hombres de armas, criados suyos. A pesar de la inferioridad numérica de sus fuerzas, Don Alonso desbarató las formaciones del príncipe de Viana, que se tenía por vencedor. Si bien Don Carlos logró huir a la fortaleza local, se redujo posteriormente a merced de las fuerzas de su padre. La segunda versión afirma que el príncipe de Viana no se quiso rendir sino a «Don Alonso de Aragón Maestre de Calatrava su hermano, y que a él dió estoque y una manopla; y el maestre se apeó del caballo y besó la rodilla al príncipe» (26). La biografía de Don Alonso confirma la última versión, subrayando que la actitud de Don Alonso hacia su hermanastro fue «con rendimiento más de vencido que de vencedor... fiando en la gran benignidad del Rey mi señor que le tratará como a hixo». De allí que Don Alonso, sin faltar a su obediencia filial, se brindaría a endulzar la prisión de su hermanastro y consolarle en su congoja (27). La actuación de Don Alonso en la batalla de Aybar permite vislumbrar nuevas facetas de su actitud caballeresca, cuando a su valentía sin par en el campo de batalla se sumó su gentil cortesía hacia su hermanastro, al cual trató «con rendimiento más de vencido que de vencedor».

La importante contribución de Don Alonso al triunfo Juanista en Aybar le valió la concesión real de la villa pirenaica de Cortes con su castillo y jurisdicción. En la merced real concedida a su hijo natural, Juan de Navarra expresó su gratitud en términos calurosos, justificando su donación «en remuneración de los muy notables y señalados servicios que con pura voluntad 
y entera lealtad y con assaz derramamiento de sangre y gasto y pérdida de la hacienda por nuestro servicio y conservación de nuestros Reynoss le habia conferido hasta el presente Don Alonso de Aragón (28). A la sazón, el otrora Maestre de Calatrava justificaba los razonamientos de su padre en las zonas fronterizas, impidiendo las incursiones de Luis de la Cerda, conde de Medinaceli, y haciendo correrías en derredor de Cuenca (1452) (29).

El acuerdo de paz con Castilla en Agreda y Almazán (septiembre-octubre 1454) llevaría a una paz provisoria en la frontera castellano-aragonesa. Por otra parte, Alfonso $V$ sacrificaba los intereses personales de su sobrino en aras de la renaciente paz. El acuerdo sustentado por el soberano aragonés hacía mención de la renuncia formal de Don Alonso al maestrazgo de Calatrava, que ya había sido adjudicado al protegido del Príncipe de Asturias, Pedro Girón (30). La muerte del rey de Aragón, acaecida el 27 de junio de 1458, convirtió a Juan de Navarra en soberano rey de Aragón, Valencia y Cataluña, mas no cambió el giro de los acontecimientos en Castilla (31). El 15 de mayo de 1460, la familia real unida hacía su entrada en Barcelona, cuando Juan de Navarra acompañado de su real consorte, Juana Enríquez, era escoltado por sus hijos, Carlos príncipe de Viana, recientemente pacificado con su padre, y el infante Fernando. A ellos les seguían los esforzados hijos naturales del monarca, Don Alonso de Aragón y Don Juan (32).

No obstante, la feliz concordia concertada entre Juan de Navarra y el príncipe de Viana sería del mismo corto alcance como lo fueron los acuerdos anteriores firmados entre padre e hijo. Los recelos mutuos y la intervención incisiva de la reina Juana (33) llevaron nuevamente al encarcelamiento del príncipe. La muerte prematura de Don Carlos el 23 de septiembre de 1461 y los odios apasionados despertados por la política de su padre, llevaron al proceso vertiginoso de la renovación de la guerra civil en Navarra y la revuelta Catalana (34). La participación de Don Alonso de Aragón en ambos casos fue decisiva y justificó la aureola heroica con la que sería galardonado en las crónicas contemporáneas.

A comienzos de 1461 Don Alonso fue puesto al mando de las fuerzas agramontesas para poner fin a la rebelión beamontesa en Navarra, incentivada por el apoyo militar prometido por Enrique IV y el encarcelamiento arbitrario del Príncipe de Viana (35). Si bien Don Alonso tuvo ganancias territoriales limitadas, logró una importante victoria sobre Gracián de Lussa, señor de Samper y otros capitanes de la parcialidad del príncipe de Viana. La victoria alcanzada por Don Alonso en el campo de batalla indujo al condestable de Navarra, Luis de Beamonte, a suplicar el reforzamiento de la ayuda castellana en el reino pirenaico, donde el campo beamontés se veía francamente ame- 
nazado (36). A pesar del éxito que coronó la gestión del condestable, la parcialidad del príncipe de Viana sufrió un nuevo revés en la batalla de Abarzuza. Con los refuerzos enviados por su cuñado, Gastón IV conde de Fox, Don Alonso se sobrepuso al ejército castellano que contaba con doscientos hombres de armas y unos cuatrocientos jinetes, de los cuales, de acuerdo al testimonio de la documentación real, ninguno pudo escapar (37). Los reveses en el campo de batalla sumados a la nueva iniciativa diplomática de Juan II, llevaron a Enrique IV a firmar un nuevo acuerdo general entre Aragón y Castilla (26 de agosto de 1461), que daba un plazo de cuatro meses a concertar el pleito navarro. Mas la muerte del príncipe de Viana antepuso las posibles decisiones de la junta nombrada a tal efecto. Posteriormente, también Juan de Beamonte juró fidelidad a Juan de Navarra, concretándose el pacto entre Agramonteses y Beamonteses (22 de noviembre de 1462). A la sazón, Juan II, libre ya de la crisis Vianesa, tendría que sobreponer la igualmente grave y prolongada afrenta que le presentaba el principado de Cataluña (38).

A comienzos de 1462 la situación de Juan de Navarra en Cataluña era francamente desesperada. El fracaso de la reina Juana Enríquez en Barcelona y su partida forzada con el príncipe Fernando, sumados al cerco hermético con que los rebeldes los tenian sometidos en Gerona, invistieron de crucial importancia las acciones militares de Don Alonso en el principado. En este sentido, la toma de Castelldásens y el triunfo en Rubinat ( 23 de julio de 1462) fueron importantes etapas en la contra-ofensiva de las fuerzas Juanistas. Destacando el rol de Don Alonso en Castelldásens, Zurita establece que «emprendió la mayor fuerza y peligro dél», así también en Rubinat, donde su coraje y acometida ayudaron a coronar con éxito el tercer y crucial ataque de las fuerzas reales (39). También en las cercanías de Barcelona fue «muy señalado el esfuerzo y valentía de Don Alonso de Aragón en las ordinarias escaramuzas que tuvo con los de la ciudad en aquella parte donde tenía sus estancias, a la puerta de Junqueras; y allí se acometían por su persona contínuos hechos de armas, peleando en las cavas y barreras con los enemigos» (40).

De esta época data también la primera relación amorosa duradera que tuvo Don Alonso (41). Estando invernando el ejército real en la zona del Ampurdán en pos de la liberación de la reina del cerco de Gerona, Don Alonso se enamoró pérdidamente de Doña María lunques, hija de los nobles en cuya hacienda se hospedaba. Dado que la doncella no retribuyó sus atenciones, Don Alonso la raptó de la casa de sus padres, «faltando a las leyes de hospedaxe». Si bien sus aspiraciones al maestrazgo de Calatrava le impidieron contraer matrimonio con Doña María, Don Alonso tuvo de ella dos hijos, 
Don Juan de Aragón, duque de Luna, quien le sucedió en el estado de Ribagorza y Doña Leonor de Aragón, a quien casó posteriormente con Don Jaime del Milá, primer conde de Albayda (42). Cabe destacar que Doña María lunques contó con el apoyo espiritual y económico del rey de Navarra y Aragón, quien consideró a sus hijos como verdaderos nietos suyos y hasta su lecho de muerte se preocupó del futuro de Don Juan de Aragón (43). Por otra parte, las dotes personales de Doña María, su organizada administración y abnegada defensa del condado de Ribargorza, la hicieron merecedora de las gracias reales, siendo galardeada por Juan II con el título de «magnifica" (44).

Mientras tanto, la revuelta catalana alcanzaba otro de sus extremos cuando en pos de la alianza de Juan II con Luix XI de Francia (45), la Generalidad de Cataluña ofrecía la corona de Aragón primeramente a Enrique IV de Castilla (11 de agosto de 1462) (46) y en pos de la traición de su lugarteniente Juan de Beamonte, al condestable Don Pedro de Portugal (27 de octubre de 1463): Don Pedro de Portugal, nieto del conde de Urgel, otrora pretendiente al trono aragonés en la elección de Caspe, «vino a Cataluña a gozar su reyno que tan mal le salió el año de 1464 y hallóla tan llena de guerras por todas partes que pudo desde luego anteber el mal fin de aquella promesa» (47). Desde la perspectiva de Juan II, la afrenta del condestable lusitano parecía ser menos apremiante que la previa acometida castellana. Más aún, liberada de la amenaza castellana, la contra-ofensiva Juanista se volcó en 1464 sobre los puntos claves de Cataluña oriental: Lérida y Cervera, que habrian de tener un rol crucial en el balance de fuerzas contra el aspirante lusitano a la corona. El ataque Juanista concentrado en Cervera llevó a los barceloneses a estrechar sus esfuerzos en la zona, acaudillados por Don Pedro. Mas en los alrededores de Villafranca las fuerzas rebeldes sufrieron varios reveses militares por las fuerzas reales al mando de Don Alonso de Aragón, el castellán de Amposta Huc de Rocabertí y Rodrigo de Rebolledo (febrero de 1464) (48). No obstante, la tenaz defensa de Cervera encomendada a Juan de Armendáriz, llevó al ejército real a concentrarse en un segundo objetivo, Lérida, «que se juzgaba el puesto más principal después de Barcelona». Debilitada por los efectos del hambre y la falta de ayuda efectiva de Barcelona, la ciudad claudicó a Juan II el 6 de julio de 1464, mientras Don Alonso de Aragón recibía la fuerza de Garden «que está en un colado al occidente fuera de la ciudad que señorea el campo y las entradas del río y de la ciudad» (49).

Entre 1465-1466 encontramos nuevamente a nuestro biografiado en los puestos claves que posibilitaron la conquista de Igualada, Cervera y el castillo de Amposta, uno de los más importantes baluartes conquistados por las fuerzas Juanistas en la guerra civil. Comentando la toma de lgualada (17 de 
julio de 1465) las fuentes contemporáneas hacen mención de un curioso episodio: el capitán local, Pere Mateu, decidió rendir las torres a las fuerzas reales y requirió su entrada para reducir a sus contrarios; más las huestes de Don Alonso temian escalar la plaza por temor a una emboscada. Visto lo cual, Don Alonso «no se contentando de hacer el oficio de muy valeroso capitán sino adelantarse como muy valiente soldado, fue el primero que apeándose del caballo llegó a la cava y tomando por sus manos una escala, animando a los suyos, socorrieron a los que habían alzado las banderas por el rey que peleaban con los de dentro» (50). El mismo día se rindió a Don Alonso el castillo de Monfalcón, mientras Cervera capitulaba el 14 de agosto de 1465, después de ocho meses de enconada resistencia (51). La Garoffa fue conquistada por Don Alonso a comienzos de 1566 (52). Hacia fines de 1466 se desmoronaba la resistencia anti-Juanista en el mediodía de Cataluña. La toma del castillo de Amposta (21 de junio de 1466), era seguida por las capitulaciones de Tortosa, "ojo derecho del cuerpo místico de Cataluña», Flix y Miravet (53). A su vez, la muerte de Pedro IV en Granollers, el 29 de junio de 1466, parecía auspiciar el broche de la enconada contienda.

La incertidumbre que rodeaba el futuro de Cataluña no privó a Don Alonso de la gratitud de su real padre. Desde el cerco del castillo de Amposta, el 17 de noviembre de 1465, Juan II le hizo merced de la baronía de Arenós, vuelta a la corona por la rebelión de Don Jaime de Aragón, hijo de Don Alonso de Aragón, duque de Gandía (54). El documento real refleja fielmente la gratitud del militante y ya anciano rey para su hijo natural: «Por quanto vos, el muy ilustre y amado hijo nuestro Don Alonso de Aragón havéis hecho bien el oficio real exercitando todo lo que ha sido menester bastantemente en estos tiempos desta rebelión y conspiración nefassdíssima entre los Catalanes contra nos y contra nuestro estado, haciendo en el de echo militar y en las demás nescissidades de nuestra casa como varonil hijo nuestro, preciándose y obstentando su ánimo como el lugar y ocassión lo pedían. Por tanto os do, mas no suficiente ni digno a buestros merecimientos según los estimamos, pero queriendo os dar alguna cosa por lo que por nos y por nuestro serbicio habéys hecho con las armas sin cessar ni haver intermición contra los soberbios y rebeldes nuestros a quien tantas veces havéis impugnado y hechóles guerra. Por estos serbicios, peligros y trabaxos y gastos sustentados y hechos por vos, deviéndose os hazer merced, os damos la presente carta nuestra para todos los tiempos valedera, de nuestra cierta ciencia deliberada consulta, assí por nos como por todos los nuestros para vos y buestros herederos donde o quales quiera, os damos y entregamos y concedimos en perpetua donación, pura, simple y irrevocable que se dize entre vivos, para vos el illustre nuestro hijo, y para quien vos quisiereys, la varonía 
de Arenozo con sus villas, campos y lugares" (55). Así mismo, el $1 .{ }^{\circ}$ de enero de 1468, Don Alonso recibió la importante suma de 50.000 florines que habría de recaudar de las villas de Igualada y Vilafranca para «sustentar la gente de armas que con vos en nuestro servicio tubísteis, particularmente en la expugnación del condado de Pallas» (56). Por último, el 27 de noviembre de 1469, Juan II hizo entrega a Don Alonso del importante condado de Ribagorza en nombre de su hijo Fernando, Rey de Sicilia, actual conde de Ribagorza, «cuyos confines nuestro Reyno de Aragón y principado de Cataluña alcansan y se axa ser llave aquellos mismos reinos y entrada y salida de los dichos Reinos de Francia y partes de Gascuña... para la deffención y utilidad de la corona del dicho Reyno de Aragón y principado de Cataluña y por el bien pacífico quieto y tranquilo estado del mismo condado de Ribagorza» (57).

No obstante, las campañas militares de Don Alonso en el principado de Cataluña no habian alcanzado aún su cenit. El 30 de julio de 1466 la Generalidad hizo un vuelco político completo y ofreció la corona aragonesa a Renato de Anjou, quien gozaba del respaldo político y militar de su escurridizo sobrino, Luis XI, rey de Francia (58). A mediados de abril de 1467, el primogénito Juan de Anjou, duque de Lorena, hacía su feliz entrada en el principado, habiendo elegido como primer meta a Gerona, importante bastión Juanista que centralizaba la embestida real en el Bajo Ampurdán. Especialmente requerido por la población local, fue alli enviado Don Alonso de Aragón, quien logró mantener la defensa de la importante plaza (59). Mas el revés del ejército real en las cercanías de Vilademat (21 de noviembre de 1467) involucró la inminente pérdida del Ampurdán. Por ese entonces, Don Alonso daba un giro positivo a los acontecimientos, cuando el 23 de mayo de 1468 vencía la hueste del conde de Vaudemont, que avanzaba hacia Sant Joan de les Abadesses (60). No obstante, la contienda estaba aún lejos del desenlace final. Los refuerzos que trajera el duque de Lorena llevaron a la capitulación de Gerona $\left(1{ }^{\circ}\right.$ de junio de 1469), posiblemente en pos de las intrigas secretas manejadas por el clan de los Margarit (61).

La muerte del duque de Lorena acaecida en Barcelona el16 de diciembre de 1470, permitiria un nuevo vuelco de fortuna a las fuerzas leales a Juan II, donde se luciría nuevamente Don Alonso de Aragón. Secundado por el conde de Prades, Don Alonso conseguía importantes éxitos en el frente del Vallés donde se le rindieron Sant Cugat, Sabadell y Granollers (noviembre de 1471) (62). Así mismo, "corría el Maestre desde San Cugat toda aquella comarca tiniéndolos en contínuas armas asta las puertas de Barcelona" (63). El 26 de noviembre, Don Alonso consiguió un importante éxito en Santa Coloma de Gramanet, en pos del cual selló el destino del Bajo Ampurdán. Cerca 
del río Besós, las tropas reales consiguieron una significativa victoria frente a las tropas barcelonesas acaudilladas por Dionisio de Portugal, Menaut de Guerri y Jacobo Galiotto, que resultó en 4.000 muertos del bando rebelde y numerosos prisioneros, entre los cuales figuraban los capitanes de las fuerzas barcelonesas. Refiriéndose a la participación de Don Alonso en la importante contienda, Zurita establece que «él, como gran capitán y guerrero animando a los suyos, hirió a los enemigos» (64). También la biografía de Don Alonso no escamotea en alabanzas respecto a la participación de nuestro biografiado en Santa Coloma de Gramanet: «Obró el maestre peleando y animando los soldados como acostumbrava. Siendo conocido se devió esta victoria a su valor a cuyo exemplo obraron todos los cabos de su exército y en particular Martín de Lanuza que con grave valor ganó el estandarte de Jacomo Galeoto matando a su alférez» (65).

Los comienzos de 1472 auspiciaron la conquista real de la zona norte del Ampurdán, que habría de despejar el camino a Barcelona. En un período de tres meses, Figueras, Peralada, Torroella, Castello y Rosas, se redujeron a la obediencia de Juan II (66). En ese entonces Juan II sufrió un completo revés frente a Peralada, después de haber sido sorprendido por las fuezas conjuntas del capitán de las fuerzas francesas, Antoine de Lau, y de los capitanes Angevinos, el conde de Campobasso y Bofillo de Giudice (4 de abril de 1472): «con quinientas lanças francezas y algunas compañías de lacayos... acometieron al amanecer al exército del rey tan de repente, que rota la guardia y desbaratada, si no acudiera el Maestre Don Alonso, corriera gran riesgo la persona del Rey, que desarmado y casi desnudo se recogió a Figuerass (67). De allí que la fidelidad filial de Don Alonso se vería coronada por el rescate de Juan II y su liberación de un peligroso cautiverio en las cercanías de Peralada, un nuevo galardón en la epopeya caballeresca de nuestro biografiado.

La reducción del Ampurdán, facilitada por la política benevolente de Juan II, y la inminente toma de Barcelona, posibilitaron la capitulación de Pedralbes (16 de octubre de 1472), que selló los 10 años de lucha intermitente en el principado (68). Mas las preocupaciones militares de Juan II no habían desaparecido aún. La ocupación francesa del Rosellón y Cerdeña presentaba para el rey de Navarra y Aragón un nuevo desafío, al cual el ya anciano monarca dedicaría sus postreros años (69).

A fines de enero de 1473 el ejército real franqueó los Pirineos al mando de Juan II y sus fieles capitanes, Don Alonso de Aragón, Joan Ramon Folc III de Cardona conde de Prades, Don Bernaldo Hugo de Rocabertí castellán de Amposta y Fernando de Rebolledo. El ejécito real hizo su entrada triunfal en Elna, Canet, Argelés, El Voló y finalmente, Perpiñán quienes abrieron re- 
gocijadamente sus puertas al soberano (70). La lucha contra los franceses pondría nuevamente a prueba el desinterés de Don Alonso y su compieta abnegación a los intereses reales, aun a costa de los suyos propios. En septiembre del mismo año, contingentes franceses marcharon hacia el condado de Ribagorza con el propósito de dividir los esfuerzos de las huestes aragonesas. Si bien Don Alonso proveyó satisfactoriamente la defensa de su condado, antepuso su obediencia filial a su interés personal y no abandonó a su padre en Perpiñán. En vista de tal decisión concluye su biografía: «...pero el Maestre, que siempre atendió más al servicio del rey su padre que a sus combeniencias, no obstante que conocía el riesgo en que estava su estado, no se apartó de la occassión, que en Rossellón avía conocido lo que importava en ella su persona» (71). Todos estos esfuerzos serían en vano. Las fuerzas aragonesas no pudieron refrenar la completa superioridad numérica francesa y a pesar de la fidelidad de la población local, la empresa del Rosillón terminaba en un fracaso rotundo con la caída de Perpiñán el 10 de marzo de 1475. A la sazón comenzaba una nueva etapa en la vida de nuestro valeroso caballero. Enviado a llamar a Castilla «a grand priessa» por el rey Fernando, su hermanastro, empeñado en la lucha contra las pretensiones lusitanas al trono en pos de la muerte de Enrique IV (72), Don Alonso habria de dedicar los últimos diez años de su vida al servicio de los Reyes Católicos.

El regreso de Don Alonso de Aragón a Castilla estaba también relacionado con sus añejas pretensiones al maestrazgo de Calatrava. El apoyo del nuevo maestre, Rodrigo Téllez Girón a la parcialidad de Doña Juana, sumado a la popularidad de Don Alonso entre los comendadores de la orden, presentaban buenas perspectivas para su restitución al deseado maestrazgo (73). No obstante, una vez más las aspiraciones personales del antiguo maestre eran sacrificadas en aras de intereses políticos. La posibilidad de devolver a Rodrigo Téllez Girón y su primo, el poderoso marqués de Villena, a la fidelidad de los Reyes Católicos, inclinaron la balanza real en desfavor de su allegado, a pesar de los importantes servicios que le debian (74). Por otra parte, Fernando e Isabel encomendaban a Don Alonso la capitanía de la Santa Hermandad, aquella importante fuerza militar que habría de tener un rol crucial en la pacificación del reino, asi como en la lucha contra los portugueses hasta 1479 (Tratado de Alcaçovas) y posteriormente, contra los últimos baluartes moros en la península (75).

Al mando de las fuerzas de la Hermandad, Don Alonso habría de cumplir un rol destacado en la lucha contra la parcialidad de Doña Juana (76). A fines de noviembre de 1475, lo encontramos estrechando el cerco de Burgos, «homenaje y cabeza del reino de Castilla». La llegada de Don Alonso 
con 50 hombres de armas y 100 jinetes, permitió la partida de Don Fernando a Zamora. Resume la biografía: «Quedó el Maestre Don Alonso sobre la fortaleza de Burgos que como cabesa de Castilla la vieja hera la más importante plaça y de mayor estimación y assí lo hazía el Rey de Portugal de tenella, y el Rey Don Fernando en desealla, que corriendo su expugnación por manos de su hermano, el maestre, le asegurava el buen suscesso. Los de dentro sentian tan grande enemigo, porque su nombre era formidable por sus haçañas y en este sitio peleó por su persona como lo solía hacer en todas las ocasiones en que se allava» (77). A pesar de la valerosa resistencia de sus defensores, la falta de refuerzos prometidos de Portugal y de Francia, llevaron a la rendición del importante baluarte en manos de la Reina Católica, el 31 de enero de 1476 (78). La toma de Burgos permitió a Don Alonso concentrar sus esfuerzos en las zonas fronterizas, donde lo encontramos con cuatrocientos jinetes estorbando las rutas de los lusitanos desde Medina del Campo, Tordesillas y Madrigal (79). El 19 de marzo Don Alonso tenía un rol clave en la toma de Zamora. De acuerdo a Zurita, «aprovechó en gran manera para que se rindiese haber llegado algunos días antes Don Alonso de Aragón con cuya presencia se entendió que no se podía defender mucho tiempo por ser muy diestro en todo género de combate y haberlo dispuesto en tan pocos días, de suerte que desconfiaron del todo de la defensa» (80). La rendición de Doña María Sarmiento y del alcázar de Toro en manos de la reina, coronó finalmente las hazañas de Don Alonso en el transcurso del año (81).

A la sazón, distinguido por su padre con el título ducal de Villahermosa (82), nuestro biografiado abandonaba sus añejas pretensiones al maestrazgo de Calatrava, para contraer matrimonio con Doña Leonor de Soto, dama del cortejo de la reina Isabel (83). Los vástagos de dicho matrimonio fueron Don Alonso de Aragón, quien sucedió a su padre en el ducado de Villahermosa y Doña María de Aragón quien contrajo enlace posteriormente con Roberto de San Severino, príncipe de Salerno. La reacción de Juan II al enlace de su hijo natural refleja un aspecto recóndito en la personalidad del monarca aragonés en las postrimerías de su vida. En una enérgica carta que dirigió a Don Alonso (marzo de 1477) el anciano rey lamentaba que ninguna otra noticia podía haberle causado mayor pesadumbre, que el ver a su hijo abandonar su profesión y obligación a la Orden de Calatrava, en pos de una dama a quien doblaba en edad. La pesadumbre del monarca estaba aparejada de aspectos prácticos, no mienos amenazantes. Juan II se oponía a la concesión de la villa de Cortes, otorgada por Don Alonso a su joven esposa en dote nupcial y así mismo proyectaba la transmisión del ducado de Villahermosa y Arenós a Juan de Aragón, hijo natural de Don Alonso y Doña María lunques (84). ¿Serían éstos, sinceros remordimientos de conciencia del rey ara- 
gonés al umbral de su muerte? La respuesta es difícil de discernir. Amén de su simpatía hacia Doña María lunques, la reacción de Juan II refleja, quizás, la frustración que le acometió ante la decisión independiente de Don Alonso, que involucraba su permanencia constante en Castilla. Por otra parte, la reacción del monarca aragonés confirma la importancia que adjudicaba al maestrazgo de Calatrava, actitud que fuera compartida por Don Alonso durante los últimos treinta años.

A pesar de las reservaciones de Juan II, el destino del duque de Villahermosa continuó estrechamente ligado al de su hermanastro, Don Fernando, al cual continuó secundando hasta las postrimetrías de la lucha contra Alfonso V. En 1477, Don Alonso sobresalía nuevamente en la toma de Cantalapiedra y Siete Iglesias, posteriormente en Escalona (1479), logros que apresuraron el completo desbande del partido lusitano en Castilla (85). Fernando del Pulgar, quien a lo largo de su crónica se refirió a nuestro biografiado como "el bastardo hermano del rey», establece, no obstante, que Don Alonso «puso así mismo gran diligencia en el sitio que tenía puesto sobre aquella fortaleza de Siete Iglesias que tenía en cargo, e en espacio de dos meses la guerreón (86). A la vez, Don Alonso comenzaba a tomar responsabilidades gubernamentales. En pos del viaje de los Reyes Católicos a Andalucía, fue nombrado gobernador de Castilla y León, junto al condestable, Don Pedro Hernández de Velasco (87). En 1481, Don Alonso acompañó a los Reyes Católicos a las Cortes de Barcelona, donde fuera jurado Don Juan como príncipe heredero. En dicha ocasión, Don Alonso fue elegido miembro del estamento nobiliario representado en las Cortes. También en 1484 tomó parte de las Cortes de Tarragona junto a los Reyes Católicos (88).

La última etapa en la vida de Don Alonso que irónicamente no logró concluir, estuvo ligada a la lucha contra los moros del reino de Granada. En 1482 Don Alonso tomó parte del cerco de Loja, «que sabiendo que se alló en esta guerra, esta provado quan valerossamente obró en ella quando sus muchos años le estorvassen al pelear por sus manos como solía» (89). Refiriéndose a la participación de Don Alonso en el funesto sitio, Alonso de Palencia nos refiere en colores vívidos la decadencia biológica de nuestro héroe: «Esta insensatez (uso de bombardas mayores para abrir una brecha en las murallas de Loja) encontró severo censor en el duque Don Alfonso de Aragón, guerrero experimentado, y a quien acompañó frecuentemente la victoria mientras mandó los ejércitos. Un padecimiento de la vista y la obesidad, disminuyendo su aptitud para la guerra, dieron pretexto a los bisoños, y por tanto, malos jueces en asuntos militares, para conceder menos autoridad a la opinión del ilustre guerrero. El cual pronosticaba que el sitio elegido para el campamento 
sería funesto a los nuestros...» (90). Demasiado anciano para tomar parte activa en la lucha, Don Alonso fue, no obstante, el arquitecto de la estrategia militar seguida por los Reyes Católicos en la guerra de Granada, cuyo desenlace no alcanzaría a festejar. Don Alonso de Aragón falleció en Linares, en la campaña que siguió a la toma de Zalea, cuando escoltaba a sus Reyes a Alcalá de Henares (1485) (91).

Los calurosos elogios fúnebres que recibió Don Alonso de la pluma de sus contemporáneos, lo acercan, indudablemente, al ideal caballeresco medieval, donde junto al mítico Mío Cid o al no menos legendario Rolando, Don Alonso de Aragón merece un lugar de preferencia. Citaremos el epitafio de Alonso de Palencia: «Fue Don Alonso afortunado en los combates con los enemigos; salvó a su padre y a su hermano de trances muy difíciles y supo triunfar de muchos peligros. Fue tenido por guerrero esforzado. Le abatió mucho la desenvoltura y loca fatuidad de su mujer, ya anciano. Ejemplo elocuente para que los ilustres capitanes cuiden de conservar su buena fama hasta el último día de su vida, porque sus hechos han de andar de boca de todoss (92). Si bien Juan II, no pudo ver el desenlace matrimonial que confería sus previsiones, los últimos días de Don Alonso de Aragón aparecen rodeados de los sinsabores que le produjeron una consorte joven y una senilidad prematura, que rodeaba de sombras un pasado glorioso.

La ingratitud de sus contemporáneos o la fatuidad de su consorte rodearon de sinsabores los últimos días de Don Alonso, mas no borraron la aureola caballeresca que rodeó al aragonés durante toda su vida. Aunque no murió en la lucha contra los moros y su muerte no pudo ser congraciada con el martirio, la biografía de Don Alonso de Aragón personaliza el ideal caballeresco del medievo tardío, ya sea por su completa abnegación a su padre y señor, Juan de Navarra o hacia los Reyes Católicos (93), su valentía en el campo de batalla o su culto del bello sexo. Teniendo en cuenta las luchas apasionadas que afectaron al reino de Castilla en sus días, entre Juan II y su hijo el Príncipe de Asturias, futuro Enrique IV, al reino de Francia, entre el rey Carlos y su hijo el delfín, futuro Luis $X I$ y al reino de Navarra, entre su propio padre, Juan de Navarra y el príncipe de Viana, Don Alonso de Aragón aparece como una figura excepcional, símbolo de fidelidad filial, valentía y amor, a quien sus dotes personales elevaron a la cúspide del ideal caballeresco medieval. Tal como concluye Jerónimo Zurita, los dones de Don Alonso de Aragón lo hacen acreedor de una «muy particular historia». 
NOTAS

(1) J. PRAWER, The Crusaders' Kingdom: European Colonialism in the Middle Ages, Nueva York 1972, págs. 6 y sig.

(2) A. GRABOIS, «De la trêve de Dieu à la paix du roi - Etude sur les transformations du mouvement de la paix au XII siècle», Mélanges René Crozet, éds. P. Gallais et Y. Riou, Poitiers 1966, I, págs. 585-95.

(3) J. HUIZINGA, El Otoño de la Edad Media, tr. José Gaos, Madrid 1981, págs. 133 y sig. M. ESPADAS BURGOS, «El sentido de la vida en el caballero medieval», La Orden de Calatrava. VIII Centenario, Publicaciones del Instituto de Estudios Manchegos, Ciudad Real 1959, págs. 68-71.

(4) La bibliografía sobre el período es extensa. Como estudio panorámico, cabe citar la monumental obra editada por R. MENÉNDEZ PIDAL, Historia de España, vol. XV, Los Trastámaras de Castilla y Aragón en el siglo XV, por LUIS SUÁREZ FERNÁNDEZ, ÁNGEL CANELLAS LÓPEZ y JAIME VICENS VIVES, Madrid 1964.

(5) JOSÉ NAVARRO LATORRE, Don Alonso de Aragón, la «espada» o lanza de Juan II. Barcelona 1983.

(6) La principal fuente a nuestra disposición es la biografía inedita, Historia del Invicto Don Alonso de Aragón Maestre de la Orden de Calatrava y Conde de Ribagorza, hijo natural del inclito Rey Don Juan el segundo de Aragón y de Navarra. Real Academia de la Historia, Colección Luis de Salazar I-35, Sign. 9-609, n. ${ }^{\circ}$ 36203, (de aquí en adelante citado como Historia). Ver la descripción del manuscrito en el Indice de la Colección de Don Luis de Salazar y Castro, ed. Baltasar Cuartero y Huerta \& Antonio de Vargas Zúniga y Montero de Espinosa, Madrid 1959. XXIII, 173. Si bien la biografía es anónima, tanto la redacción como el estilo de la misma esbozan la posibilidad que fuera escrita a comienzos del siglo XVII por un admirador del rey Don Juan II de Aragón.

(7) MOSÉN DIEGO DE VALERA, Crónica de Enrique $N$, ed. Juan de Mata Carriazo Madrid 1941, págs. $65,205,255,289$. ANDRÉS BERNÁLDEZ, Memorias del Reinado de los Reyes Catolicos, ed. Manuel Gómez Moreno y Juan de Mata Carriazo, Madrid 1962, c. XVIII, p. 51. ALONSO DE PALENCIA, Crónica de Enrique IV, tr. D. A. Paz y Meliá, Madrid 1904, 5 vols., I. p. 100.

(8) Historia, fol. 3 r. JERÓNIMO ZURITA, Anales de la Corona de Aragón, Zaragoza 1579, ed. Ángel Canellas López, Zaragoza 1975, XV-29, p. 313. LUCIO SíCULO MARINEO, Crónica d'Aragón, 1523, repr. Barcelona 1974, fol. 66 v.

(9) Historia, fol. $4 \mathrm{v}$.

(10) Religionis zelus rite, 3/9/1443, Archivo Histórico Nacional, Documentos eclesiásticos de Calatrava, n. ${ }^{\circ} 126$. 
(11) Bullarium Ordinis Militiae de Calatrava, opus D. Ignatii Josephi de Ortega et al., Aranjuez 1747-1761, p. 254.

(12) Historia, $3 \mathrm{v}$.

(13) Historia, 4 v. $-5 \mathrm{r}$.

(14) Consultar nota $\mathrm{n} .{ }^{\circ} 10$.

(15) A.H.N., Documentos eclesiásticos de Calatrava, n. ${ }^{\circ} 128$, fols. 4-7. En otro artículo, «A Chapter in the Juridical History of the Order of Calatrava - The Election of Don Alonso de Aragón» hemos discutido en detalle los distintos aspectos de esta discutida elección (en prensa).

(16) PEDRO CARRILLO DE HUETE, Crónica del Halconero de Juan /l, ed. Juan de Mata Carriazo, p. 357 y sig., págs. 417-39. Ver así mismo, J. VICENS VIVES, Juan II de Aragón Monarquía y revolución en la España del siglo XV. Barcelona 1953, págs. 96-123.

(17) ALONSO DE PALENCIA, Crónica, I, p. 74. Consultar así mismo, J. O'CALLAGHAN, "Don Pedro Girón, Master of the Order of Calatrava, 1445-1466", Hispania, 21 (1961), págs. 346 y sig.

(18) ZURITA, XIX-61, p. 245. Algunos cronistas contemporáneos se identificaron con las reivindicaciones de Don Alonso. Alonso de Palencia, por ejemplo, lo designa como «legítimo maestre de Calatrava», actitud común también a Mosén Diego de Valera, ver Alonso de Palencia, Crónica, III, p. 154, IV, p. 19. MOSÉN DIEGO DE VALERA, Crónica de los Reyes Católicos, ed. Juan de Mata Carriazo, Madrid 1927, p. 40.

(19) JAIME CARUANA GÓMEZ DE BARREDA, "La Orden de Calatrava en Alcañiz», Teruel, 8 (1952), págs. 132-33.

(20) Historia, fols. 5 r. -5 v.

(21) ZURITA, XV-39, p. 352.

(22) Crónica de Don Álvaro de Luna Condestable de Castilla, ed. Juan de Mata Carriazo, Madrid 1940, págs. 224-29.

(23) A. de Palencia, Crónica, I, págs. 99-100.

(24) ZURITA, XV-63, 64, págs. 438-44. Sobre la situación en el reino de Navarra consultar, V. VIVES, p. 139 y sig. FERNANDO RUANO PRIETO, Don Juan // de Aragón y el Príncipe de Viana, Bilbao 1897. GEORGES DESDEVISES DU DEZERT, Don Carlos d'Aragón, Prince de Viane, París 1889, págs. 123-313. JOSÉ RAMÓN CASTRO, Carlos III el Noble, Rey de Navarra, Pamplona 1967, págs. 11 y sig.

(25) Sobre la batalla de Aybar y su desarrollo, consultar, MANUEL IRIBARREN, EI Príncipe de Viana, Barcelona 1947, págs. 88-97.

(26) ZURITA, XV-65, p. 446.

(27) Historia, fols. 8 v. $-9 \mathrm{r}$.

(28) Historia, fol. $10 \mathrm{r}$.

(29) ZURITA, XVI-1, p. 11. Historia, fol. 8 r.

(30) A. de Palencia, Crónica, l, págs. 273-74. FRANCISCO R. DE UHAGón Órdenes Militares - Discursos leidos ante la Real Academia de la Historia, Madrid 1898, págs. 75-6. Historia, fol. $12 \mathrm{v}$.

(31) Ver la confirmación de los acuerdos de Agreda y Almazán, firmada en Alfaro, el 20 de mayo, 1457, Real Academia de la Historia, Memorias de Don Enrique IV de Castilla - Colección diplomática, Madrid 1835-1913, vol. II, págs. 149-51. Cabe destacar que la preocupación de Juan de Navarra por recuperar el maestrazgo era genuina. Ya en 1450, había tratado de volver a Don Alonso a la dirección de Calatrava a través de los tratados de paz con Castilla; si bien dicha propuesta resultó ser un ardid del condestable para desviar la atención del rey de Navarra a sus planes, Don Alonso entró en Pastrana y tomó la posesión de la villa, pero fue derrotado por el Maestre Pedro Girón en Almagro, ver Crónica de Don Álvaro de Luna, p. 251. ZURITA, XV-63, págs. 439-40.

(32) VICENS VIVES, Juan II, p. 218.

(33) Sobre la personalidad de la reina y su influencia sobre Juan II ver el detallado estudio de Carmen Muñoz Roca-Tallada, Doña Juana Enriquez, Madrid 1945. 
(34) MANUEL IRIBARREN, EI Príncipe, págs. 159-202. G. DESDEVISES DU DEZERT, Don Carlos, págs. 308-52.

(35) A. de Palencia, Crónica, I, p. 340.

(36) ZURITA, XVII-23, p. 353. Historia, 12 r.

(37) ZURITA, XVII-26, págs. 359-60. A. de Palencia, Crónica, I, p. 350.

(38) Real Academia de la Historia, Memorias, págs. 304-311. Sobre la voluminosa literatura histórica de la revuelta catalana, consultar especialmente, SANTIAGO SOBREQUES, «Los orígenes de la revolución catalana del siglo XV: las cortes de Barcelona de 1454-1458", Estudios de Historia Moderna, 2 (1952), 1-96. CARMEN BATTLE, "La ideología de la busca: La crisis municipal de Barcelona en el siglo XV», Estudios de historia moderna, 5 (1955), 165-196, así como la edificante reseña de la situación del principado por C. BATTLE GALLART, La crisis social y económica de Barcelona a mediados del siglo XV, 2 vols. Barcelona 1973.

(39) ZURITA, XVIi-40, p. 415, 418.

(40) ZURITA, XVII-44, p. 428.

(41) Si bien desconocemos los nombres de los otros amores de Don Alonso, los cronistas contemporáneos nos brindan los nombres de sus otros hijos naturales, a saber, Don Alonso de Aragón, obispo de Tortosa, que fue promovido a la iglesia de Tarazona, Don Hernando, prior de Cataluña y Don Enrique, abad de Nuestra Señora de la O, que falleció electo obispo de Cephalú. ZURITA, XX-64, págs. 496-97. Historia, fols. 34 r. - 34 v. J. NAVARRO LATORRE, págs. 51-52.

(42) Historia, fols. $13 \mathrm{v} .-14 \mathrm{v}$.

(43) En su lecho de muerte Juan II requirió a su hijo y heredero, Fernando el Católico, que abrogase por el casamiento de su nieto, Don Juan, con Doña María López de Gurrea, «rica fembra», considerada la heredera más preciada en toda España, Historia, fols. 31 r. - $31 \mathrm{v}$. así como fols. 14 r. -14 v., 25 v., 29 r., 30 v.

(44) Historia, fols. 32 r. -32 v.

(45) JOSEPH CALMETTE, Louis XI, Jean I/ et la revolution catalane, Paris 1902 (repr. 1977), 57-67.

(46) Real Academia de la Historia, Memorias, págs. 248 y sig.

(47) Historia, fol. $17 \mathrm{r}$.

(48) ZURITA, XVII-53, p. 464.

(49) Historia, fol. 17 v. ZURITA, XVII-55, p. 474. Ver asi mismo, E. MATEU LLOPIS, «Los recursos económicos de Juan II en Lérida y Tárrega durante las turbaciones del Principado en 1465», Hispania, 8 (1942), 407-57.

(50) Historia, fol. 18 v. ZURITA, XVIII-3, p. 519.

(51) ZURITA, loc. cit.

(52) ZURITA, XVIII-6, p. 431.

(53) Historia, fols. $24 \mathrm{r},-21 \mathrm{r}$.

(54) ZURITA, XVIII-4, p. 522.

(55) Historia, fols. $19 \mathrm{v},-20 \mathrm{r}$.

(56) Historia, fols. $21 \mathrm{v},-22 \mathrm{r}$.

(57) Historia, fols. 22 v. - 23 v. Sobre el condado de Ribagorza, su extensión y poderío, ver, M. SERRANO Y SANZ, Noticias y Documentos históricos del Condado de Ribagorza hasta la muerte de Sancho Garcés III, Madrid 1912. El 8 de julio de 1473, en pos de los festejos que siguieron a la retirada de las fuerzas francesas de Perpiñán, Juan II y su primogénito, el rey Fernando, extendieron la concesión del condado de Ribagorza a Don Juan de Aragón, hijo natural de Don Alonso y Doña Maria lunques, ver, Historia, fols. 25 v. - 26 v. ZURITA, XVIII-56, p. 720.

(58) La oferta de los catalanes al conde de Anjou aparece en J. CALMETTE, Louis XI, págs. 265-77. Sobre las implicaciones de tal oferta consultar VICENS VIVES. Fernando el Católico, Príncipe de Aragón, Rey de Sicilia, 1458-1478, Madrid، 1952, págs. 255-59. Ver así mismo, J. ERNESTO MARTÍNEZ FERRANDO, Nueva visión y sintesis del gobierno intruso de Renato d'Anjou, Barcelona 1941.

(59) Historia, fol. 21 r. ZURITA, XVIII-11, p. 558; XVIII-17, p. 577; XVIII-23, págs. 603-04. 
(60) ZURITA, XVIII-16, p. 571. Historia, fol. $21 \mathrm{r}$.

(61) ÁNGELES MASIÁ DE ROS, Gerona en la guerra civil en tiempos de Juan II, Barcelona 1943 , págs. 160 y sig.

(62) ZURITA, XVIII-37, p. 658. Historia, fol. $24 \mathrm{v}$.

(63) Historia, fol. 24 r. A. de Palencia, Crónica, II, p. 482.

(64) ZURITA, XVIII-37, págs. 657-58.

(65) Historia, fol. $24 \mathrm{v}$.

(66) Historia, loc. cit.

(67) ZURITA, XVIIl-38, p. 660. Historia, loc. cit.

(68) ZURITA, XVIII-44, págs. 683-84. Sobre la capitulación de Pedralbes y la política Juanista, consultar, VICENS VIVES, Juan 11, págs. 337-40.

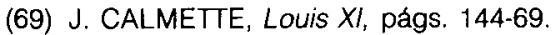

(70) Historia, fols. 25 r. - 25 v. ZURITA, XVIII-54, 55, págs. 712, 716. A. de Palencia, Crónica, III, págs. 154-55. Ver así mismo J. CALMETTE, “La monarchie aragonaise et la campagne des français en Roussillon en 1474-1475", Annales du Midi 61 (1948), págs. 96 y sig.

(71) Historia, fols. 26 v. - 27 r. ZURITA, XVIII-59, p. 731.

(72) MOSÉN DIEGO DE VALERA, Crónica de los Reyes Católicos, p. 38 . Alonso de Palencia, Crónica, IV, p. 58. ZURITA, XIX-30, p. 135. Historia, fols. 27 r. - 27 v. Sobre los antecedentes del conflicto, consultar, ORESTES FERRARA, Un pleito sucesorio: Enrique $\mathrm{N}$, Isabel de Castilla y la Beltraneja, Madrid 1945. TARSICIO DE AZCONA, Isabel la Católica, Madrid 1964, págs. 229-307.

(73) FERNANDO DEL PULGAR, Crónica de los Reyes Católicos, ed. Juan de Mata Carriazo, Madrid 1943, 2 vols., I, p. 66. ANDRÉS BERNÁLDEZ, Memorias, p. 28. C. TORREZ SUÁREZ, "Don Rodrigo Téllez Girón, Maestre de Calatrava", Anuario de Estudios Medievales, 11 (1981), 777-82.

(74) La desilusión de Don Alonso ante la ingratitud de los Reyes Católicos, le hizo forjar planes de inmediato regreso a Aragón, ver, Historia, fols. 28 v. - 29 r. ZURITA, XIX-49, p. 204.

(75) FERNANDO DEL PULGAR, Crónica, págs, 230-43. Sobre la Santa Hermandad, su administración e influencia en la política real, ver MARVIN LUNENFELD, The Council of the Santa Hermandad, Miami 1970, esp. págs. 9-14. Sobre la guerra de Granada, MANUEL BALLESTEROS GAIBROIS, Isabel de Castilla, Reina Católica de España, 2da. ed. Madrid 1970, págs. $93-$ 96. TARSICIO DE AZCONA, Isabel, págs. 503 y sig.

(76) Sobre la invasión portuguesa y las consecuentes batallas ver, CÉSAR SILIO CORTÉS, Isabel la Católica, Madrid 1943, ed. 1967, págs. 131-98.

(77) Historia, fols. 27 v. - 28 r.; ver el juicio similar de Mosén Diego de Valera, Crónica de los Reyes Católicos, p. 47; A. de Palencia, Crónica, IV, págs. 89-97.

(78) FERNANDO DEL PULGAR, Crónica, págs. 151, 165, 173, 178.

(79) Historia, fol. 28 r. ZURITA, XIX-40, 43, págs. 171, 177. FERNANDO DEL PULGAR, Crónica, p. 198. MOSÉN DIEGO DE VALERA, Crónica de los Reyes Católicos, p. 84. A. de Palencia, Crónica, págs. 139-140, 149.

(80) ZURITA, XIX-45, p. 187-88. Historia, fol. 28 v. A. de Palencia, Crónica, IV, p. 183.

(81) Historia, fol. 29 r. A. de Palencia, Crónica, IV, 298-301. MOSÉN DIEGO DE VALERA, Crónica de los Reyes Católicos, págs. 94-95. ZURITA, XIX-57, p. 232. Ver así mismo J. FERNÁNDEZ DOMÍNGUEZ, La guerra civil a la muerte de Enrique IV: Zamora, Toro, Castronuño, Zamora 1929. VICENTE DIEZ CARBAJO, «La batalla de Toro», Ejercito, 35 (1942), p. 35 y sig.

(82) Historia, fol. 29 v. ZURITA, XIX-61, p. 245.

(83) El gran aprecio de la reina para su dama quedó corroborado años más tarde cuando Doña Leonor de Soto fue escogida como su único cortejo en la ceremonia de bautismo del principe heredero Don Juan, ver, ANDRÉS BERNALDEZ, Memorias, c. XXXIII, p. 75.

(84) ZURITA, XX-3, 4, págs. 262-65. Historia, fols. $30 \mathrm{r}$. $-31 \mathrm{v}$.

(85) ZURITA, XX-6, 13, 30, págs. 268-69, 299, 365. Historia, fol. 30 r. FERNANDO DEL PULGAR, Crónica, págs. 243, 289, 294, 358. MOSÉN DIEGO DE VALERA, Crónica de los Reyes Católicos, págs. 124-125. 
(86) FERNANDO DEL PULGAR, Crónica, págs. 294-95.

(87) ZURITA, XX-12, p. 292. A. de Palencia, Crónica, IV, págs. 425-426.

(88) Historia, fol. 34 r. ZURITA, XX-41, p. 403.

(89) ZURITA, XX-56, p. 465. FERNANDO DEL PULGAR, Crónica, págs. 23 y sig.

(90) A. de Palencia, Crónica, V, p. 48.

(91) ZURITA, XX-44, p. 417. Historia, fol. 34 r. De acuerdo al intinerario de los Reyes Católicos, éstos estuvieron en Linares entre el 8 y el 10 de octubre, fecha en que se sitúa la muerte de Don Alonso. Ver ANTONIO RUMEU DE ARMAS, Itinerario de los Reyes Católicos, 1474-1516. Madrid 1974, p. 135.

(92) A. de Palencia, Crónica, V, p. 216. Historia, fol. 34 v. ZURITA, XX-64, p. 496.

(93) Quizás ésta fue la intención del anónimo autor de la Historia cuando comenzó su obra recalcando la fidelidad de su abuelo, Fernando de Antequera, hacia su difunto hermano y su sucesor, el futuro Juan Il de Castilla, Historia, fols. $1 \mathrm{r}$. - $1 \mathrm{v}$. 